\title{
Effectiveness of Listening to Background Music on Recall Ability Among High School Students
}

\section{Savita Pohekar ${ }^{1}$, Vaishnavi Joshi², Vaishnavi Kantode ${ }^{2}$, Ravina Kardekar², Mayuri Kelzarkar², Muskan Khan²}

\begin{abstract}
'Associate Professor, Department of Medical-Surgical Nursing, Datta Meghe University of Medical Sciences (Deemed to be University), Smt.Radhikabai Meghe Memorial College of Nursing Sawangi (Meghe), Wardha, lndia; ${ }^{B}$ Basic BSc Nursing 4th Year Students, Datta Meghe University of Medical Sciences (Deemed to be University), Smt.Radhikabai Meghe Memorial College of Nursing Sawangi (Meghe), Wardha, India.
\end{abstract}

\section{ABSTRACT}

Background: Background music refers to music played during some activity by the listener. There are few studies which evaluated the effect of music therapy on academic performance and this impact was not taken into account high school students. The aim of this study was thus to deal with this imbalance by evaluated its effect on cognitive tasks of declarative memory and speed of processing in high school student with the help of background music.

Objectives: To evaluate the recall ability of high school students from the influence of background music and associate the efficacy of background music with high school pupils' ability to remember with selected demographic variables

Methods: The study was performed on 60 randomly selected high school students using a random sampling technique, the organized interview schedule was used to collect the demographic characteristics and nonsense word test used to check their recall skills.

Results: The overall comparison of test 1 and test 2 shows that the tabulated value for $n=60-1$ i.e. 59 d.f. is 2.00 which value is lower than estimated i.e. 11.98 at $5 \%$ level of significance for overall non-sense test score which is a statistically acceptable level of significance. A significant association was found between listening to background music on recall ability of high school students with selected variables such as age, sex, and area of residence.

Conclusion: We conclude therefore that background music on high school student's ability to recall was effective.

Key Words: Efficacy, Background music, Potential to remember, Students of high school

\section{INTRODUCTION}

More than 2000 years ago Greeks understood the positive influence of music on the human body and got the place in their curriculum. But music therapy was not used routinely except as a supplemental note in conventional medicine traditional care protocols. Music was used as a method of instruction in early teaching-learning. Cognitive benefits of both active and passive music list. ${ }^{1}$ To find out how music and learning are correlated with each other several types of research have been done and the result of those researches revealed that music produces several positive effects on a human's body, mind, and spirit. Music works on both the left and right hemispheres of the brain at the same time and as a result of this music maximizes learning and improves memory. ${ }^{2}$
The present study explores the role of background music plays on these aspects of high school students. This study aims to observe the effect of listening to background music on improving recall ability among high school students. Objectives for the study were set as to evaluate the recall ability of high school students, to assess the effectiveness of background music on recall ability among high school students, and to associate the effectiveness of background music on recall ability among high school students with selected demographic variables.

\section{Operational Definitions:}

Effectiveness: In this study, it applies to the degree that background music has its impact on recall ability among

\section{Corresponding Author:}

Savita Pohekar, Datta Meghe University of Medical Sciences (Deemed to be University), Smt.Radhikabai Meghe Memorial College of Nursing Sawangi (Meghe), Wardha, India.

ISSN: 2231-2196 (Print)

Received: 20.08 .2020
ISSN: 0975-5241 (Online)

Revised: 07.10 .2020
Accepted: 09.11.2020 
high school students measuring scores by using nonsense word test.

Background music: In this study, it refers to any kind of music that is played while learning. Here the researcher uses the background music I, instrumental Music by Peder B. Helland was used

Recall ability: In this study, recall ability means to remember what has been studied. Here the students recall nonsense word test consists of 15 nonsense words and instructed them to read it in silence for 5 minutes and then they turned the list and recalled whatever they read for 5 minutes and then they were asked to write it down whatever they remember from the list of Nonsense words.

\section{High school student:}

In this study, a high school student normally means school children between the ages of 14 to 16 years.

\section{CONCEPTUAL FRAMEWORK}

The conceptual system is conceptual models or conceptual schemes (we use the terms here interchangeably) to reflect a less formal attempt to organize phenomena than theories. As the name suggests, the conceptual framework deals with principles of abstraction which are constructed because of their importance to a specific theme.

This study is focused on evaluating the effectiveness of listening to background music on recall ability among high school students. The researcher selected Kenny's open system model theory in this study, as this theory shows the process of evaluating the listening to background music on recall ability among high school students.

The open device model definition is primarily input, performance, output, and feedback. In open system theory, input refers to matter, energy, and information entering through its boundary into the system. Throughput is data processing; output refers to the processed matter and information. After processing of the data, the device returns [matter, energy, and information] to the end

Input: In this study, the information given is too high school students through nonsense tests Following the pre-test. Different demographic variables are assumed, such as (age, sex, place of residence), and also their previous knowledge regarding improving recall ability by using background music will affect their recall ability before pretest given through the nonsense test without background music.

Throughput: In this study it is the mechanism through which information and experience are transmitted. Nonsense test with background music is given after pretest without background music. Here researcher used nonsense tests with background music to check the improvement in recall ability among high school students.

Output: Through this analysis, it is the phase through which we will determine the effect of background music on recall ability of high school students with the help of nonsense word tests. This can be determined by the score of information gained by the post-test. Check the outcome after the intervention. There may be five possibilities for very bad, bad, decent, good, or excellent information scores among high school students. This can be very mediocre, mediocre, and average due to lack of interest, lack of focus, and lack of motivation. The difference between information and practice scores pre-test and post-test may remain very mediocre, mediocre, and average, or it may become decent and excellent. Feedback: Difference in group post-test scores as seen from group recall ability score. The group's recall capacity score can differ with the demographic variables. The input in this analysis is a method of preserving the efficacy of the teaching modalities for background music. The principles were updated as follows in this study; it is presumed.

\section{MATERIAL AND METHOD}

Quantitative approach and True experimental Posttest-only without control group design was adopted for the study. The content validity of the tool was established by giving to experts. $^{3}$

Nonsense Word Test given by Hermann Ebbinghaus was used to assess the recall ability and background music i,e Instrumental Music by Peder B. Helland was used as it is a well-known fact and many of the studies and researches support that person can study better in a relaxed mind and positive mood. So the investigator used this music to enhance a positive mood and a relaxed mind. The condition for this supposed intervention is that background music influences anxiety and mood, which in turn impacts learning outcomes. The reliability coefficient of the standardized tool (nonsense word test) using Cronbach's alpha was 0.88 . The ethical clearance has been obtained from the ethical committee and pilot study was conducted on 6 high school students to find out the feasibility of conducting the final study. The findings of the pilot study revealed that it was feasible to conduct the study. After obtaining the ethical clearance from the ethical committee of Datta Meghe Institute of Medical Sciences Deemed to be University, the final study was conducted in AnandraoMeghe School Borgaon (Meghe) Wardha. A total of sixty samples were randomly assigned through a simple random sampling technique using a chit method. Formal consent was obtained from the sample. A structured interview schedule was used to assess the selected variables (demographic characteristics such as age, gender, place of residence). Data was collected between dated $23^{\text {rd }}$ 
December to $7^{\text {th }}$ January 2020 .sixty(60) high school students aged 14 to 16 years of age selected for the study. Explained the proposed study and nature of the study to ensure better co-operation during data collection. A list of Nonsense word tests consists of 15 nonsense words and instructed them to read it in silence for 5 minutes and then they turned the list and recalled whatever they read for 5 minutes and then they were asked to write it down whatever they remember from the list of Nonsense words. After fifteen days the same list of Nonsense words was given to the same students, the same protocol followed but the only change which was done was given background music while students were reading and recalling the list of Nonsense words.

\section{Statistical analysis}

Data were tabulated using Microsoft Office Excel 2013 for Windows and Statistical analysis was performed using $\mathrm{R}$ Studio (Version 3.5.0) - (C) 2009-2018 RStudio, Inc. Crosstabulation and across study variables were checked according to the Chi-square test of significance. $\mathrm{P}<5 \%$ was considered statistically significant. Responses were clubbed according to predefined qualitative variables. Data analyzed and interpreted according to the objectives and hypothesis of the study using descriptive and inferential statistical methods.

According to the Chi-square test of significance, cross-tabulation and across study variables were tested. $\mathrm{P}<5$ percent has been found as statistically significant. Answers were clubbed based on predefined qualitative variables analyzing data. Data analyzed and interpreted using descriptive and inferential statistical techniques, based on the study's goals and hypothesis. ${ }^{4}$

\section{RESULTS}

Findings revealed that in this study, majority of the students $29(48.3)$ were in the age group of 15 years, $39(65 \%)$ were female students, $51(85 \%)$ students were residing in a rural area and $9(15 \%)$ were from the urban area.The recall ability among high school students without background music in test 1 shows that $90 \%$ of the high school students had a poor level of recall ability and $10 \%$ had an average level of recall ability. In test 2 with background music, $13.33 \%$ of the high school students had good recall ability and $56.670 \%$ had average recall ability after background music. As shown below in figure 1 and 2 .

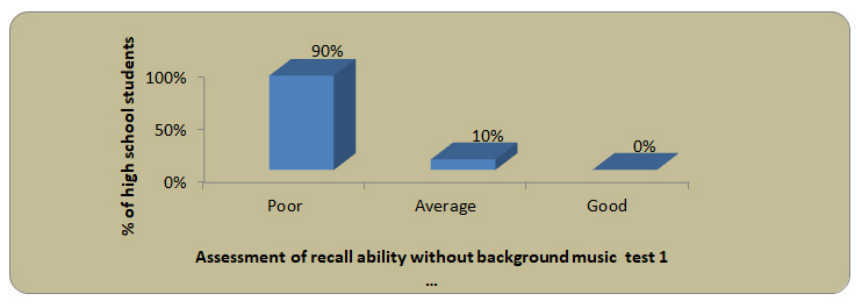

Figure 1: Assessment of recall ability without background music test 1.

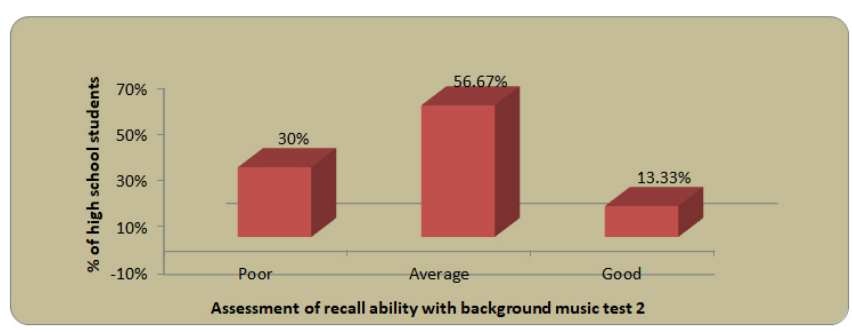

Figure 2: Assessment of recall ability with background music test 2 .

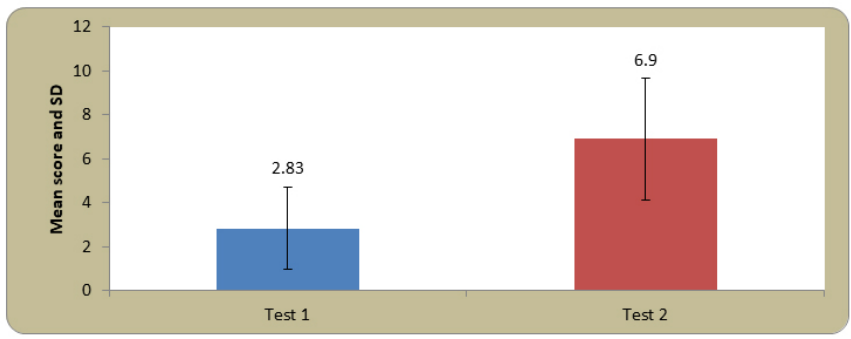

Figure 3: Significance of difference between background music on recall ability among high school students in test 1 and test 2 .

\section{Effect of background music on recall ability}

Table 1.shows the comparison of background music on recall ability among high school students in test 1 and test 2 . Mean, standard deviation, and mean difference values are compared and the student's paired ' $t$ ' test is applied at a 5\% level of significance. The tabulated value for $\mathrm{n}=60-1$ i.e. 59 d.f. is 2.00 which is less than calculated value i.e. 11.98 at a $5 \%$ level of significance for overall non-sense test score which is a statistically acceptable level of significance. Hence it is statistically interpreted that the background music on recall ability among high school students was effective. Thus the $\mathrm{H} 1$ is accepted.

Table 1: Significance of difference between background music on recall ability among high school students in test land test $2(n=60)$

\begin{tabular}{cccccc} 
Mean & Overall & SD & $\begin{array}{c}\text { Mean } \\
\text { Difference }\end{array}$ & t-value & p-value \\
\hline 2.83 & Test 1 & 1.89 & $4.06 \pm 2.62$ & 11.98 & $\begin{array}{c}0.0001 \\
\text { S,p<0.05 }\end{array}$ \\
6.90 & Test 2 & 2.79 & & & \\
\hline
\end{tabular}


Table 2: Association of background music on recall ability with demographic variables

\begin{tabular}{|c|c|c|c|c|c|c|}
\hline Demographic Variables & Frequency & $\operatorname{Mean} \pm \mathrm{SD}$ & $\begin{array}{c}\text { F-value/ } \\
\text { t-value }\end{array}$ & df & $\begin{array}{c}\text { F-tab/t-tab } \\
\text { value }\end{array}$ & p-value \\
\hline \multicolumn{7}{|l|}{ Age in years } \\
\hline $14 \mathrm{yrs}$ & 23 & $7 \cdot 30 \pm 2.47$ & 1.00 & 2,57 & 0.48 & 0.61 \\
\hline $15 \mathrm{yrs}$ & 29 & $6.75 \pm 2.91$ & & & & \multirow{2}{*}{$\mathrm{S}, \mathrm{p}<0.05$} \\
\hline $16 y r s$ & 08 & $6.25 \pm 3.37$ & & & & \\
\hline \multicolumn{7}{|l|}{ Gender } \\
\hline Male & 21 & $7.09 \pm 2.18$ & 0.39 & 58 & 2.00 & 0.69 \\
\hline Female & 39 & $6.79 \pm 3.08$ & & & & $S, p<0.05$ \\
\hline \multicolumn{7}{|l|}{ Area of residence } \\
\hline Urban & 09 & $6.66 \pm 2.23$ & 0.27 & 58 & 2.00 & 0.78 \\
\hline Rural & 51 & $6.94 \pm 2.89$ & & & & $\mathrm{~S}, \mathrm{p}<0.05$ \\
\hline
\end{tabular}

Above table no 2 shows the association of background music on recall ability with demographic characteristics of high school students. The tabulated values were less than the calculated' values at a 5\% level of significance. Also, the calculated "p-value which was less than the acceptable level of significance i.e. ' $p$ ' $=0.05$. Hence it is interpreted that the socio-demographic characteristics of high school students are statistically associated with their level of recall ability with background music test2.

\section{DISCUSSION}

The present study found that the majority of the sample $56.670 \%$ had average recall ability and $13.33 \%$ of the high school students had a good level of recall ability with background music test 2 as compared to without background music test 1 . Such results were identical to those from the study Arumagam Indira et.al in the year 2018 conducted study on the effectiveness of music therapy on academic performance of nursing students using experimental and control group suggested that the music is effective in academic performance of a student's. ${ }^{3}$

The study was done by Sarah I. Wilson and Margot Prior in the year 2006 suggests that there is considerable interest in the potential non-musical cognitive and academic benefits of music listening and instruction to children. ${ }^{4}$ The positive effect of music participation on overall achievement has been proven in Barr et al's experimental study. ${ }^{5}$ The effect of music on anticipation and listeners' mood is based on the tempo (fast vs. slow) and mode (major vs. minus) of the music itself. ${ }^{6}$

There is ample literature showing a direct effect on music and its ability to reduce a state of anxiety. Unqualified academic achievement of students after engaging in music learning is clouded with clarity, although research groups claimed that active participation in music helps improve cognitive skills in math and verbal tasks. ${ }^{7}$ When music is used to enhance academic performance, a group of students may benefit. ${ }^{3} \mathrm{~A}$ study on the assessment of types of learning modes in medical students also emphasized that students in the classroom learn the best when they are fully aware of the strengths and weaknesses of their learning modes. It is best to avoid labelling students. Students can choose one style of learning but must respond to a mix of different activities. ${ }^{8}$

\section{CONCLUSION}

The study findings have shown that background music is effective in enhancing recall capacity and can be used as a useful measure to build interest and focus among students in their academic performance. This approach has more favourable results on the potential of the recall to enhance the academic performance of the student than the conventional method of learning. The research can be performed in the future with different background music with larger sample size, along with some more forms of examination. A prospective longitudinal multi-centred study at the national level is needed to shed light on the role of Indian classical music in the academic growth of our future generations from grassroots to higher education, to combat the ever-growing burden of courses and curricula. The fundamental problem in Indian infrastructure research, however, is a lack of logistics that we need to improve to justify the study.

Ethical Clearance: Taken from DattaMeghe Institute of Medical Sciences Deemed to be University, Institutional Ethical Committee, Sawangi (Meghe), Wardha. Reference No.DMIMS(DU)/IEC/sept-2019/8484 


\section{ACKNOWLEDGEMENTS}

We thank the research department of the institution for approving this study and the head of the Anandrao Meghe College, Borgaon (Meghe) Wardha, for allowing us the work to be done. We appreciate the important support of the psychologist. The authors thankfully recognize the participation of all volunteers in this study. Authors are grateful to IJCRR editorial board members and IJCRR team of reviewers who have helped to bring quality to this manuscript.

Funding source: Self-funding

\section{Conflict of Interest: None}

\section{REFERENCES}

1. Črnčec R, Wilson SJ, Prior M. The Cognitive and Academic Benefits of Music to Children: Facts and fiction. Educ Psychol 2006 Aug 1;26(4):579-94.
2. Music and the Brain: What Happens When You're Listening to Music [Internet]. Pegasus Magazine. [cited 2020 Aug 5]. Available from: https://www.ucf.edu/pegasus/your-brain-on-music/

3. Indira A, Pydimarry PV, Katari K, Hemanathan R, Pal R, Ghosh A, et al. Effectiveness of music therapy on the academic performance of nursing students. Int J Acad Med 2018; 4(3): 278-283.

4. Crncec R, Wilson SJ, Prior M, The Cognitive and Academic Benefits of Music to Children: Facts and fiction. Int J Exp Educ Psychol 2006;26(4): 579-594.

5. Sundaram K, Saravanakumar DA. Folk music on enhancing academic performance in social science among tribal children. Indian J Res 2019; 8(9): 18-20.

6. Gabrielsson A, Lindström E. The role of structure in the musical expression of emotions. In: Handbook of music and emotion: Theory, research, applications. New York, NY, US: Oxford University Press; 2010; 367-400.

7. Eerola T, Friberg A, Bresin R. Emotional expression in music: contribution, linearity, and additivity of primary musical cues. Front Psychol [Internet]. 2013;24:4.

8. Malhotra V, Tripathi Y. Assessment of learning modes in medical students. Int J Clin Diagn Res 2013; 5(7):115-122. 